\title{
Distal corpus cavernosum fibrosis and erectile dysfunction secondary to non-ischaemic priapism
}

\author{
Evangelos Zacharakis ${ }^{1,2}$, David J Ralph ${ }^{2}$, Miles Walkden ${ }^{3}$, Asif Muneer ${ }^{2}$ \\ ${ }^{1}$ Department of Urology, Guy's Hospital, Kings College London; \\ 2 Department of Urology, University College London Hospitals; \\ ${ }^{3}$ Department of Radiology, University College London Hospitals, UK.
}

\begin{abstract}
Summary Non-ischaemic priapism is a rare type of priapism and is associated with penile or perineal trauma. The absence of ischaemia should theoretically prevent smooth muscle necrosis and corporal fibrosis which occurs in ischaemic priapism. The aim of this study was to first report a patient series with non-ischaemic priapism that developed distal corpus cavernosum fibrosis and erectile dysfunction. Over a 5 year period, a cohort of 6 patients diagnosed with non-ischaemic priapism presented to a single centre. The diagnosis was based on a clinical history, penile examination with confirmation using a combination of cavernosal blood gas analysis, colour duplex ultrasonography of the penis and angiography. Patients were followed up in clinic at regular intervals with clinical examination and repeat imaging. Following a median follow up of 4 weeks (range 2-12) the patients reported either the development of erectile dysfunction with distal penile flaccidity. Five patients required the use of PDE-5 inhibitors to achieve full tumescence. The remaining patient eventually underwent insertion of a penile prosthesis due to the failure of pharmacotherapies. Based on these findings we suggest that superselective embolisation of non-ischaemic priapism cases occasionally should be performed after a shorter period of conservative treatment.
\end{abstract}

KEY WORDS: Non-ischaemic; Perineal trauma; Superselective embolization.

Submitted 4 March 2015; Accepted 30 April 2015

\section{INTRODUCTION}

Priapism is a urological emergency and requires a prompt diagnosis and intervention. Non-ischaemic (high flow) priapism is rare and occurs as a result of unregulated arterial inflow into the corpus cavernosum, commonly after direct perineal or penile trauma (1-3). Unlike ischaemic priapism, where there is stasis of ischaemic blood within the corpus cavernosum, in nonischaemic priapism the corpus cavernosum remains perfused with oxygenated blood and therefore patients are commonly managed conservatively until spontaneous resolution occurs (1-3). If there is a failure of resolution with conservative measures then superselective embolisation is performed. The time interval to allow a conservative approach is not defined and therefore patients can be left for several months without intervention until the fistula spontaneously closes. This study presents the out- comes in a unique cohort of patients diagnosed with non-ischaemic priapism who have paradoxically developed fibrosis within the distal corpus cavernosum following conservative treatment.

\section{Case presentation}

A subgroup of 6 patients selected from a priapism database diagnosed with non-ischaemic priapism required treatment for erectile dysfunction using either pharmacotherapy or a penile prosthesis. The initial diagnosis of non-ischaemic priapism was based on the clinical history and examination and penile duplex ultrasonography. Where there was diagnostic doubt, intracavernosal $\mathrm{pO}_{2}$ and $\mathrm{pH}$ levels were also measured in 5 patients. Once the diagnosis was confirmed, patients were followed up regularly in clinic and underwent serial penile duplex studies with penile MRI being performed in 4 patients due to the development of early distal penile flaccidity.

Non-resolution of the priapism at a median 4.5 weeks (range 2-12 weeks) resulted in all patients requiring angiography and superselective embolisation. Selective internal pudendal angiography used local anaesthesia and a retrograde femoral artery puncture. A 5-French sheath was inserted under fluoroscopic control and selectively run through the internal pudendal artery. The arteriogram demonstrated a significant leak (blush), confirming the laceration of the cavernosal artery and the formation of the arterial-lacunar fistula. The therapeutic embolization was performed with a superselective catheterisation of the cavernosal artery using a microcatheter $(2.7 \mathrm{Fr})$ distally to the site of the fistula followed by Gelfoam $^{\circledR}$ embolisation. Immediately following the embolisation a repeat angiogram was performed to confirm the absence of an arterial leakage. Following successful embolisation patients were followed up in clinic. In 2 patients repeat embolisation was required due to persistent high flow priapism within 2 weeks following the initial procedure. In the remaining 4 patients embolisation resulted in resolution of the priapism immediately after the procedure. Following the resolution of the priapism, this cohort of patients developed either erectile dysfunction $(n=1)$ or suboptimal erections due to distal penile flaccidity $(n=5)$ according to the IIEF 5 questionnaire (Table 1). These patients were initially treated using 
Table 1.

Patient's clinical details.

\begin{tabular}{|lcccccc|}
\hline Patient & Age (yrs) & Aetiology & $\begin{array}{c}\text { Duration of priapism } \\
\text { up to the first embolization (weeks) }\end{array}$ & $\begin{array}{c}\text { Material used } \\
\text { for embolisation }\end{array}$ & $\begin{array}{c}\text { IIEF } \mathbf{5} \text { score } \\
\text { (6 months post priapism) }\end{array}$ & Treatment \\
\hline 1 & 20 & Perineal injury & 2 & Gel foam & 20 & PDE 5 inhibitors \\
\hline 2 & 41 & Perineal injury & 4 & Gel foam & 3 & Penile prosthesis \\
\hline 3 & 56 & Idiopathic & 4 & Gel foam & 19 & PDE 5 inhibitors \\
\hline 4 & 30 & Penile fracture & 3 & Gel foam & 21 & PDE 5 inhibitors \\
\hline 5 & 39 & Perineal injury & 5 & Gel foam & 18 & PDE 5 inhibitors \\
\hline 6 & 52 & Perineal injury & 12 & Gel foam & 23 & Intracavernosal Alprostadil injections \\
\hline
\end{tabular}

PDE-5 inhibitors $(n=5)$ followed by intracavernosal alprostadil $(n=1)$. A total of 6 patients were identified from a subgroup analysis of the data. The mean age at diagnosis was 39.2 years (range 20-56). The duration of the priapism and the aetiology for each case are listed in Table 1. The majority of the patients presented with a prolonged erection following penile or perineal trauma $(\mathrm{n}=5)$ which was not associated with pain and therefore clinically in keeping with the absence of an ischaemic environment. Penile duplex ultrasonography was used to confirm high systolic velocities in the corpus caver-

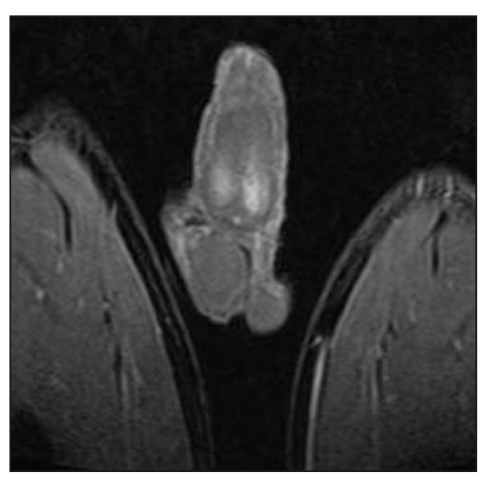

Figure 1.

T1 post contrast MRI shows patchy reduced enhancement of both distal corpora compatible with fibrosis.
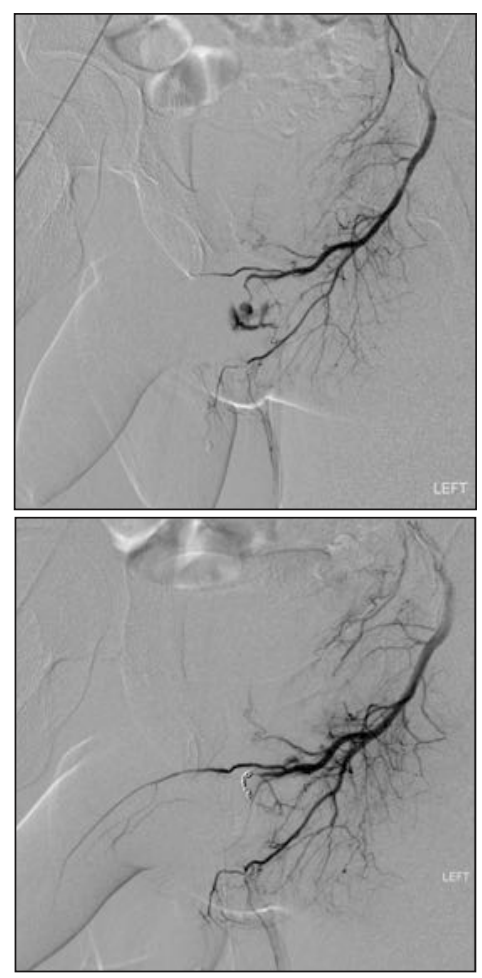

Selective angiogram of the left internal pudendal artery showing a large fistula arising from a branch of the main cavernosal artery.

Post embolisation internal pudendal angiogram showing successful occlusion of the fistula using microcoils.

Note the main cavernosal artery is still patent. nosum (range $50-75 \mathrm{ml} / \mathrm{sec}$ ). All of the patients had a fistula demonstrated on ultrasonography and probe compression of the fistula resulted in temporary resolution in one patient. In 4 patients presenting with distal flaccidity a penile MRI scan was performed to assess the corporal smooth muscle for fibrosis and demonstrate the fistula (Figure 1). The time point at which superselective embolisation was performed for each patient is shown in Table 1 together with the post procedure erectile function according the IIEF-5 score. Two patients undergoing superselective embolisation required a second attempt before the fistula was closed and the priapism resolved (Figure 2). Five patients responded to PDE-5 inhibitors which resolved the distal flaccidity and erectile dysfunction. One patient who developed erectile dysfunction failed oral pharmacotherapies and intracavernosal injections and after 6 months underwent insertion of a penile prosthesis. Discussion and supplementary references are posted in Supplementary Materials on www.aiua.it

\section{Conclusions}

We suggest close clinical follow up of patients presenting with non-ischaemic priapism combined with reimaging using penile Doppler and penile MRI. Features suggesting distal smooth muscle fibrosis either on imaging or the development of distal flaccidity should lead to earlier superselective embolisation to prevent long term erectile dysfunction.

\section{REFERENCES}

1. Bastuba MD, Saenz de Tejada I, Dinlenc CZ, et al. Arterial priapism: diagnosis, treatment and long-term follow up. J Urol. 1994; 151:1231-7.

2. Witt MA, Goldstein I, Saenz dT, I, Greenfield A, Krane RJ. Traumatic laceration of intracavernosal arteries: the pathophysiology of nonischemic, high flow, arterial priapism. J Urol. 1990; 143:129-132.

3. Montague DK, Jarow J, Broderick GA, et al. American Urological Association guideline on the management of priapism. J Urol. 2003; 170:1318

\section{Correspondence}

Evangelos Zacharakis, MD

Department of Urology, Guy's Hospital, Kings College, London, UK

David J Ralph, MD (Corresponding Author) - dralph@andrology.co.uk Department of Urology, University College London Hospitals

The Institute of Urology, 145 Harley St London, W1G 6BJ, UK

Miles Walkden, MD

Department of Radiology, University College London Hospitals, London, UK Asif Muneer, MD

Department of Urology, University College London Hospitals, London, UK 